\title{
Pemberdayaan Lintas Sektoral dalam Upaya Mewujudkan Masyarakat Peduli Kesehatan dan Keselamatan Berkendara
}

\author{
Nina Dwi Lestari ${ }^{1}$, Arif Wahyu Setyo Budi², Al Afik ${ }^{2}$ \\ 1, 2 Universitas Muhammadiyah Yogyakarta
}

\begin{tabular}{|c|c|}
\hline Article History & ABSTRACT \\
\hline \multirow[t]{2}{*}{$\begin{array}{l}\text { Received 06.09.2019 } \\
\text { Received in revised form } \\
29.11 .2019 \\
\text { Accepted 04.12.2019 } \\
\text { Available online 16.12.2019 }\end{array}$} & $\begin{array}{l}\text { CROSS SECTORAL EMPOWERMENT IN AN EFFORT TO REALIZE A } \\
\text { COMMUNITY THAT CARES ABOUT HEALTH AND SAFETY DRIVING. } \\
\text { Traffic accidents are a global phenomenon with increasing events that can result } \\
\text { in losses and deaths. The most dominant human factor is related to traffic accident } \\
\text { between vehicle and physical environment. WHO reports that around } 1.2 \text { million } \\
\text { people die each year from road accidents and are a leading cause of death among } \\
\text { young people aged } 15-29 \text { years. Partners in this program are residents of Rt } 24 \text {, } \\
\text { RW 12, Tegowanu, Kaliagung, Sentolo, Kulon Progo. The problems faced by } \\
\text { partners are the high driving accidents in the partner area, due to geographical } \\
\text { conditions of the road, vehicles that pass at high speeds from both directions, and } \\
\text { poor driving behavior. The methods used in this program are community } \\
\text { education, demonstrations, case simulations and family counseling. The result of } \\
\text { this program are that there is an increase in partner's knowledge related to driving } \\
\text { health and safety, as much as } 80 \% \text { of participants are able to re-evacuate the } \\
\text { techniques of evacuation, transportation and first aid in an accident at the } \\
\text { location. It requires the efforts of the relevant parties to continue to accustom the } \\
\text { culture of healthy and safety driving. }\end{array}$ \\
\hline & $\begin{array}{l}\text { KEYWORDS: Cross-Sectoral, Community Empowerment, Driving, Health, } \\
\text { Safety. }\end{array}$ \\
\hline
\end{tabular}

This is an open access article distributed under the terms of the Creative Commons Attribution 4.0 International License, which permits unrestricted use, distribution, and reproduction in any medium, provided the original work is properly cited. (c) 2019 Nina Dwi Lestari, Arif Wahyu Setyo Budi, Al Afik.

\section{PENDAHULUAN}

Kecelakaan lalu lintas merupakan fenomena global seiring dengan terjadinya pergeseran pola penyakit dari penyakit menular ke penyakit tidak menular (Russeng, 2011 dalam, kecelakaan yang dapat menimbulkan kerugian dan kematian. Faktor manusia yang paling dominan berhubungan dengan kejadian kecelakaan lalu lintas diantara faktor kendaraan dan faktor lingkungan fisik (Marsaid, Hidayat, \& Ahsan, 2013). Data Global Status Report on Road Safety Tahun 2015 menunjukkan, sekitar 1,2 juta orang

\footnotetext{
${ }^{1}$ Corresponding author: Program Studi Ilmu Keperawatan, Fakultas Kedokteran dan Ilmu Kesehatan Universitas Muhammadiyah Yogyakarta. Email: ninadwilestari@umy.ac.id
} 
meninggal setiap tahunnya karena kecelakaan di jalan raya dan merupakan penyebab utama kematian di kalangan anak muda pada usia 15-29 tahun. Jika tidak dilakukan penanganan yang baik, diperkirakan pada tahun 2030 kematian akibat kecelakaan di jalan raya akan meningkat dan menjadi tujuh penyebab kematian di dunia. Berdasarkan laporan WHO saat ini kecelakaan transportasi jalan di dunia telah mencapai 1,5 juta korban meninggal dan 35 juta korban luka-luka/cacat akibat kecelakaan lalu lintas pertahun.

Menurut data Kepolisian, di Indonesia, rata-rata 3 orang meninggal setiap jam akibat kecelakaan jalan. Data tersebut juga menyatakan bahwa besarnya jumlah kecelakaan tersebut disebabkan oleh beberapa hal, yaitu: 61 persen kecelakaan disebabkan oleh faktor manusia yaitu yang terkait dengan kemampuan serta karakter pengemudi, 9 persen disebabkan karena faktor kendaraan (terkait dengan pemenuhan persyaratan teknik laik jalan), dan 30 persen disebabkan oleh faktor prasarana dan lingkungan (Kominfo, 2017).

Wilayah RT 24, RW 12 Dusun Tegowanu merupakan salah satu wilayah di Desa Kaliagung, yang merupakan wilayah paling barat Kecamatan Sentolo, Kabupaten Kulon Progo. Kondisi geografis di wilayah ini adalah dilalui jalur alternative yang menghubungkan antara wilayah Yogyakarta dengan Purworejo, dimana jalur ini dilalui oleh kendaraan dengan arus lalu lintas yang ramai, kecepatan kendaraan yang tinggi dan kondisi jalan yang curam. Kondisi ini memicu tingginya angka kecelakaan berkendara di wilayah ini, tidak hanya dialami oleh penduduk setempat, namun juga oleh penduduk di luar wilayah ini. Bahkan korban seringnya adalah anak usia sekolah, yang seharusnya belum diperkenankan mengemudikan kendaraan bermotor.

Kondisi di atas diperparah dengan tingginya angka kepemilikan kendaraan bermotor di tiap keluarga, kurangnya pengetahuan keluarga dalam keselamatan berkendara, minimnya perilaku warga yang mengindahkan etika keselamatan berlalu lintas, minimnya kesadaran penggunaan alat keselamatan berkendara, dan pola asuh permisif keluarga dalam penggunaan kendaraan bermotor pada anak usia sekolah. Warga masyarakat di wilayah ini juga kerap dihadapkan dengan kondisi gawat darurat korban kecelakaan lalu lintas namun tidak banyak tindakan yang bisa dilakukan untuk memberikan pertolongan pertama, mengingat minimnya pengetahuan dan kemampuan masyarakat dalam memberikan pertolongan pertama korban kecelakaan berkendara. Jarak pelayanan kesehatan dari wilayah mitra cukup jauh yaitu berkisa 6-7 km sehingga membutuhkan kemampuan masyarakat setempat untuk bisa melakukan pertolongan pertama dalam golden period bagi korban kecelakaan supaya tidak terjadi kecacatan lebih berat bahkan kematian di lokasi.

Beberapa faktor yang menjadi penyebab dari kecelakaan lalu lintas adalah faktor manusia, faktor kendaraan, faktor jalan (sarana prasarana) dan faktor lingkungan (cuaca) (UU RI No.22 2009). Berbagai upaya telah dilakukan untuk mengurangi angka kecelakan lalu lintas atau meminimalisir kemungkinan kerugian fisik maupun finansial. Menurut Undang-Undang RI Nomor 22 tahun 2009 pasal 203 ayat 2, salah satu bentuk program nasional Keselamatan Lalu Lintas dan Angkutan Jalan adalah Cara Berkendara dengan Selamat (Safety Riding). Safety riding adalah perilaku mengemudi secara selamat yang bisa membantu untuk menghindari terjadinya kecelakaan lalu lintas. Mencakup hal-hal yang berkaitan dengan tatacara berkendara yang aman, perlengkapan yang harus ada saat berkendara dan kondisi kendaraan yang memungkinkan untuk digunakan. Safety Riding dirancang untuk meningkatkan kesadaran pengendara terhadap segala kemungkinan 
yang terjadi selama berkendara (Sumiyanto, Mahawati, \& Hartini, 2014). Inti dari safety riding itu sendiri adalah mengutamakan keselamatan, yaitu keselamatan diri dan juga pengguna jalan lain (Kusmagi 2010).

Berdasarkan latar belakang masalah mitra di atas, upaya promosi kesehatan terkait keselamatan berkendara perlu dilakukan. Hal ini sejalan dengan peran perawat yang tertuang dalam pedoman intervensi keperawatan (Nursing Intervention Classification), bahwa perawat memiliki kompetensi dalam vehicle safety promotion dengan melibatkan pihak terkait salah satunya kepolisian (Butcher et al, 2018). Kepolisian juga memiliki kewenangan dalam hal melakukan upaya pedidikan masyarakat dalam hal keselamatan berkendara (safety riding). Perawat dalam hal ini bisa memberikan promosi tentang keselamatan berkendara dengan lebih menekankan pada pola asuh keluarga dalam pencegahan penggunaan kendaraan dalam usia sekolah, peningkatan kesadaran masyarakat dalam menggunakan alat pelindung kesehatan dan keselamatan berkendara serta memberdayakan masyarakat dalam pertolongan pertama pada kecelakaan di lokasi kejadian.

\section{METODE PELAKSANAAN}

Program ini dilaksanakan pada periode Bulan Maret samapai dengan Juni 2019. Mitra dalam program ini adalah masyarakat di RT 24, RW 12, Kaliagung, Sentolo, Kulon Progo. Program Kemitraan Masyarakat ini dilaksanakan melalui beberapa tahapan kegiatan diantaranya adalah melakukan pengkajian lanjutan mengenai kejadian kecelakaan berkendara di wilayah mitra, melakukan pengkajian lanjutan mengenai pengetahuan masyarakat dalam hal kesehatan dan keselamatan berkendara dan kemampuan pertolongan pertama pada kecelakaan berkendara melalui pretest, mediasi dengan pihak kepolisian, pendidikan masyarakat terkait kesehatan dan keselamatan berkendara oleh perawat dan kepolisian, simulasi dan pelatihan teknik evakuasi, transportasi dan penanganan pertama kecelakaan berkendara di lokasi kejadian, konseling keluarga yang memiliki anak usia sekolah yang telah menggunakan kendaraan bermotor melalui kunjungan rumah.

Metode pertama yang dilakukan setelah tahapan persiapan selesai dilakukan adalah mediasi. Mediasi dilakukan dengan memfasilitasi masyarakat untuk mendapatkan informasi mengenai safety riding dan etika berlalu lintas dengan pihak kepolisian. Pengabdi melakukan mediasi dengan pihak Kepolisian khususnya Seksi Pendidikan Masyarakat Subdirektorat Pendidikan dan Rekayasa, Direktorat Lalu Lintas Polda D.I Yogyakarta untuk menjadi narasumber terkait materi tersebut dalam kegiatan pendidikan masyarakat.

Metode yang kedua adalah metode pendidikan masyarakat yang dilakukan secara bersama-sama oleh pengabdi (perawat) dan polisi. Pendidikan masyarakat yang dilakukan dengan sasaran warga RT. 24, RW. 12, Dusun Tegowanu, Desa Kaliagung, Kecamatan Sentolo, Kulon Progo terutama warga masyarakat yang telah aktif berkendara di segala usia dan diprioritaskan yang bertempat tinggal di pinggir jalan sepanjang Jalan Sentolo-Pengasih yang membentang di wilayah mitra. Alasan prioritas ini adalah supaya warga di sekitar jalan raya ini dapat menerapkan pelatihan-pelatihan yang diberikan oleh pemateri terutama dalam menangani korban kecelakaan lalu lintas di lokasi kejadian (di 
wilayah mitra) sebelum mendapatkan penatalaksanaan tenaga medis di pelayanan kesehatan.

Materi pendidikan kesehatan yang pertama adalah mengenai morbiditas dan mortalitas akibat kejadian kecelakaan berkendara yang ditinjau dari aspek kesehatan yang disampaikan oleh perawat, safety riding, dan etika berlalu lintas yang disampaikan oleh pihak kepolisian, pentingnya penggunaan alat pelindung diri (APD) untuk kesehatan dan keselamatan saat menggunakan kendaraan bermotor yang disampaikan perawat. Evaluasi dilakukan dengan soal tertulis dalam bentuk pretest dan posttest. Diolah dengan analisis deskriptif yang menyajikan hasil distribusi dan frekuensi pengetahuan masyarakat sebelum dan sesudah diberikan pendidikan masyarakat.

Metode yang ketiga adalah pelatihan dan simulasi teknik evakuasi, mobilisasi, transportasi dan pertolongan pertama pada kecelakaan di lokasi kejadian yang didampingi oleh 1 pemateri dan 4 fasilitator dengan difasilitasi peralatan pendukung seperti alat pertolongan pertama pada kecelakaan (P3K), bed evakuasi, peralatan balut bidai, dan contoh alat-alat darurat yang bisa digunakan masyarakat saat menolong kecelakaan yang diperoleh dari lingkungan sekitar. Evaluasi dilakukan tidak dengan tertulis namun dilakukan dengan pertanyaan lisan dan observasi bagaimana kemampuan peserta melakukan redemostrasi teknik evakuasi, mobilisasi dan pertolongan pertama pada kecelakaan di lokasi kejadian.

Metode yang terakhir adalah konseling keluarga yang dilakukan melalui Home visit. Home visit dilakukan dengan melakukan konseling keluarga yang memiliki anak usia sekolah dan remaja yang telah menggunakan kendaraan bermotor. Kegiatan ini bertujuan untuk meningkatkan peran serta keluarga terutama orang tua dalam mengontrol akses penggunaan kendaraan bermotor pada anak usia sekolah dan remaja dengan penerapan pola asuh yang sesuai.

\section{HASIL DAN PEMBAHASAN}

Kegiatan pengabdian masyarakat ini memiliki 3 kegiatan pokok diantaranya adalah pendidikan masyarakat, simulasi dan konseling. Adapun hasil yang diperoleh di setiap metode tersebut adalah:

\section{Pendidikan Masyarakat}

Kegiatan pertama dilakukan melalui pendidikan masyarakat yang dilakukan sasaran warga RT. 24, RW. 12, Dusun Tegowanu, Desa Kaliagung, Kecamatan Sentolo, Kulon Progo terutama warga masyarakat yang telah aktif berkendara di segala usia dan diprioritaskan yang bertempat tinggal di pinggir jalan sepanjang Jalan Sentolo-Pengasih yang membentang di wilayah mitra. Alasan prioritas ini adalah supaya warga di sekitar jalan raya ini dapat menerapkan pelatihan-pelatihan yang diberikan oleh pemateri terutama dalam menangani korban kecelakaan lalu lintas di lokasi kejadian (di wilayah mitra) sebelum mendapatkan penatalaksanaan tenaga medis di pelayanan kesehatan. Materi pendidikan kesehatan yang pertama adalah mengenai morbiditas dan mortalitas akibat kejadian kecelakaan berkendara yang ditinjau dari aspek kesehatan, safety riding dan etika berlalu lintas yang disampaikan oleh pihak kepolisian, pentingnya penggunaan alat pelindung diri (APD) untuk kesehatan dan keselamatan saat menggunakan kendaraan bermotor. 


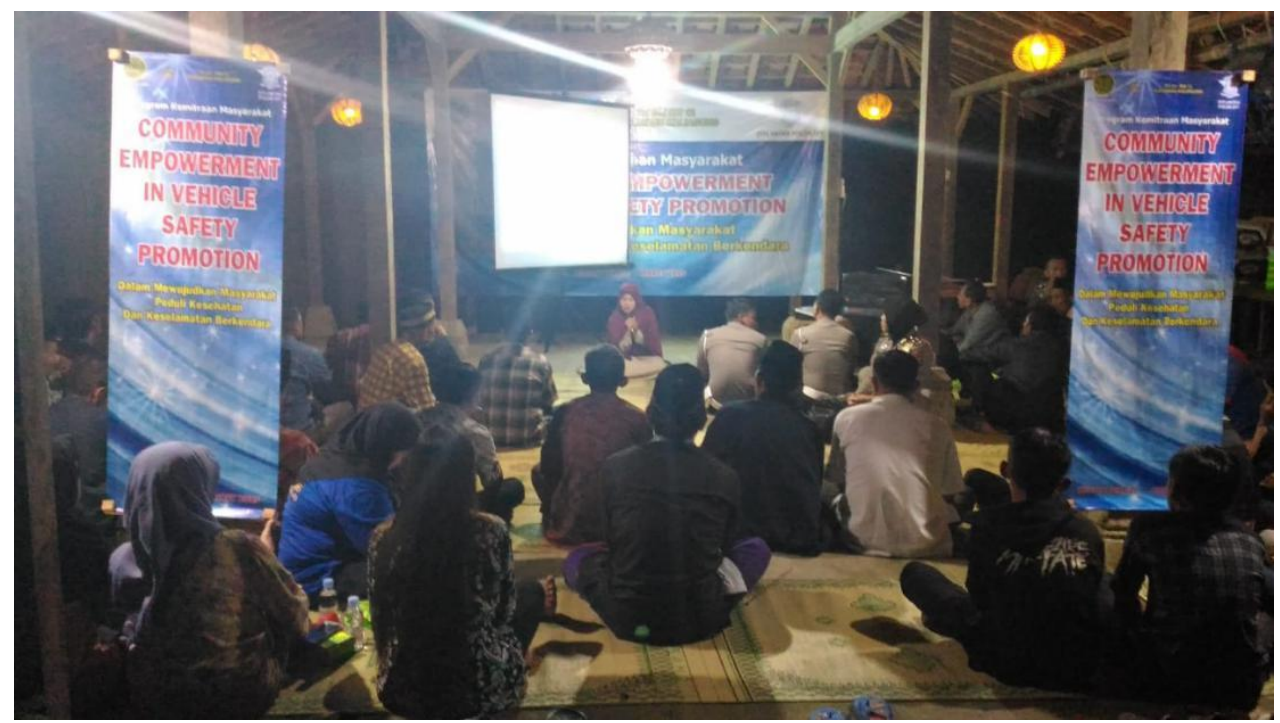

Gambar 1. Kegiatan Pendidikan Masyarakat Mengenai Kesehatan dan Keselamatan Berkendara

Sebelum diberikan materi, warga masyarakat yang mengikuti kegiatan diberikan pretest dan diberikan posttest sesudahnya. Adapun hasil rata-rata nilai pretest dan posttest tersebut adalah:

Tabel 1. Gambaran Pengetahuan Masyarakat terkait Kesehatan dan Keselamatan Berkendara antara Sebelum dan Sesudah diberikan Pendidikan Masyarakat

\begin{tabular}{llllll}
\hline \multirow{2}{*}{ No } & Variabel & \multicolumn{2}{c}{ Sebelum } & \multicolumn{2}{c}{ Sesudah } \\
\cline { 3 - 5 } & & Baik & Kurang & Baik & Kurang \\
\hline 1 & $\begin{array}{l}\text { Pengetahuan tentang Kesehatan } \\
\text { dan Keselamatan Berkendara }\end{array}$ & $42,4 \%$ & $57,6 \%$ & $73,6 \%$ & $26,4 \%$ \\
\hline
\end{tabular}

\section{Sumber: Data primer}

Pengetahuan masyarakat terkait kesehatan dan keselamatan berkendara sebelum dilakukan pendidikan masyarakat sebagian besar dalam kategori kurang baik. Lain halnya setelah dilakukan implementasi pendidikan masyarakat, sebagian besar dalam kategori baik. Hal ini menunjukkan bahwa implementasi pendidikan masyarakat ini memberikan efek positif terhadap pengetahuan masyarakat terhadap kesehatan dan keselamatan berkendara.

\section{Pelatihan dan Simulasi}

Metode pelaksanaan yang dilakukan selain dengan pendidikan masyakarat, juga dilakukan pelatihan dan simulasi teknik evakuasi, mobilisasi dan pertolongan pertama pada kecelakaan di lokasi kejadian. Warga masyarakat nampak antusias mengikuti materi ini karena kegiatan dilakukan dalam bentuk diskusi interaktif dan praktik langsung melalui simulasi yang didampingi oleh 1 pemateri dan 4 fasilitator sehingga semua warga memiliki kesempatan melakukan redemostrasi materi yang diberikan dengan difasilitasi peralatan pendukung. 


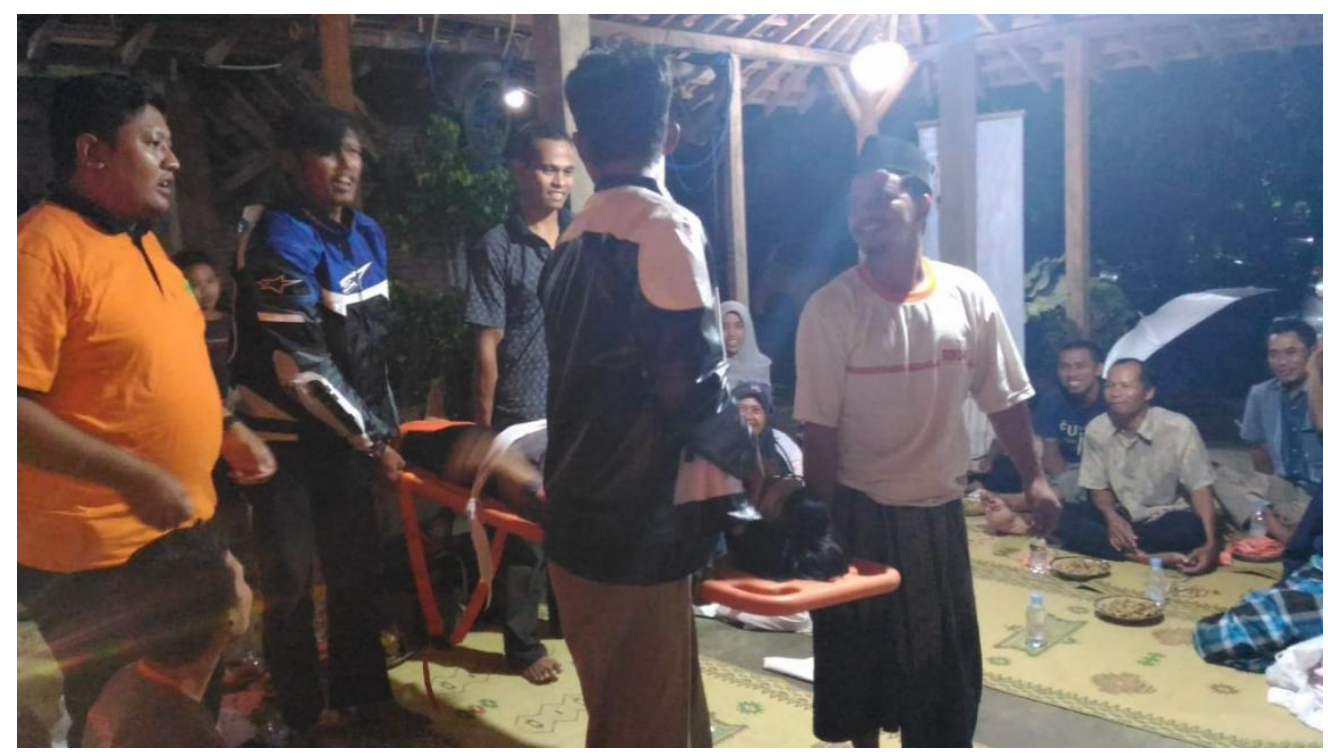

Gambar 2. Kegiatan Pelatihan dan Simulasi Evakuasi, Transportasi dan Pertolongan Pertama pada Kecelakaan di Lokasi Kejadian

Evaluasi dilakukan tidak dengan tertulis namun dilakukan dengan pertanyaan lisan dan observasi bagaimana kemampuan peserta melakukan redemostrasi teknik evakuasi, mobilisasi dan pertolongan pertama pada kecelakaan di lokasi kejadian. Hasil observasi menunjukkan sebanyak 65\% s.d 70\% peserta mampu mendemostrasikan kembali teknik evakuasi, mobilisasi dan pertolongan pertama pada kecelakaan dan $80 \%$ peserta mampu memberikan argument yang tepat terhadap evaluasi lisan dari fasilitator terkait pelaksanaan praktik teknik evakuasi, mobilisasi dan pertolongan pertama pada kecelakaan di lokasi kejadian

\section{Home visit}

Home visit dilakukan dengan melakukan konseling keluarga yang memiliki anak usia sekolah dan remaja yang telah menggunakan kendaraan bermotor. Kegiatan ini bertujuan untuk meningkatkan peran serta keluarga terutama orang tua dalam mengontrol akses penggunaan kendaraan bermotor pada anak usia sekolah dan remaja diutamakan pada anak usia yang memang belum mendapatkan ijin untuk menggunakan kendaraan bermotor namun telah aktif menggunakan sepeda motor secara mandiri. Hal ini diharapkan dapat mengurangi jumlah angka kecelakaan berkendara pada usia ini. Pendekatan yang dilakukan pengabdi dalam materi konselingnya adalah lebih ditekankan pada pola asuh orang tua dan perilaku anak atau remaja itu sendiri. Dalam proses ini, ada diskusi interaktif antara orang tua dan perawat dimana orang tua hendaknya merubah pola pengasuhan yang sifatnya dominan permisif untuk bisa lebih bijak lagi mengawasi anaknya dalam penggunaan kendaraan bermotor. Fokus konseling pada anak usia sekolah dan remajanya adalah lebih mendiskusikan keuntungan dan kerugian menggunakan kendaraan bermotor sebelum waktunya terutama dari aspek kesehatan dan keselamatan.

Home visit dilakukan pada lima sampel keluarga dengan anak usia sekolah dan remaja di wilayah mitra. Keseluruhan orang tua pada lima sampel keluarga yang dikunjungi tersebut mengaku kesulitan dalam mengendalikan penggunaan kendaraan 
motor pada anaknya karena faktor lingkungan pergaulan. Rata-rata anak seusia tersebut sudah mahir dan diperkenankan menggunakan kendaraan bermotor bahkan dibawa ke sekolah. Orang tua mengatakan bahwa sekolah sudah melarang, namun masyarakat sekitar sekolah menyediakan lahan parkir khusus untuk sepeda motor anak sekolah di luar komplek sekolah. Hal ini menimbulkan keresahan tersendiri bagi orang tua.

Tabel 2. Level Kemandirian Keluarga Sebelum dan Sesudah dilakukan Konseling

\begin{tabular}{llll}
\hline \multirow{2}{*}{ No } & Inisial KK & \multicolumn{2}{c}{ Level Kemandirian Keluarga } \\
\cline { 3 - 4 } & & Sebelum & Sesudah \\
\hline 1 & Tn S1 & Mandiri 1 & Mandiri 3 \\
\hline 2 & Tn S2 & Mandiri 1 & Mandiri 2 \\
\hline 3 & Ny N & Mandiri 1 & Mandiri 2 \\
\hline 4 & Ny R & Mandiri 1 & Mandiri 2 \\
\hline 5 & Tn W & Mandiri 1 & Mandiri 2 \\
\hline
\end{tabular}

Semua keluarga memiliki kemandirian dalam tingkat 1 sebelum diberikan konseling terkait kesehatan dan keselamatan berkendara dengan pendekatan pola asuh orang tua. Setelah dilakukan konseling sbegian besar keluarga dalam kategori 2. Hasil evaluasi setelah dilakukan kunjungan keluarga menunjukkan bahwa 4 dari 5 orang tua mengatakan menyadari bahwa penggunaan kendaraan bermotor pada anak sebelum saatnya lebih banyak menimbulkan dampak negatif dibandingkan dampak positifnya. Pada akhirnya, para orang tua berkomitmen akan mengawasi anak dalam penggunaan kendaraan bermotor terutama di jalan raya utama, karena arus lalu lintas semakin ramai. Orang tua akan berusaha memberikan aturan yang lebih disiplin lagi untuk anaknya dalam hal penggunaan kendaraan bermotor.

\section{SIMPULAN}

Tingginya angka kejadian kecelakaan lalu lintas di berbagai usia semakin meningkat dari tahun ke tahun. Hal ini menjadi masalah yang serius yang perlu dipikirkan oleh berbagai pihak tidak hanya dari kepolisian. Tenaga kesehatan khususnya perawat memiliki andil yang sangat besar dalam mengatasi masalah ini melaui upaya promotif, prventif dan rehabilitative. Tentunya hal ini akan memberikan hasil yang efektif dengan adanya kerjasama dari berbagai pihak di dalamya yaitu perawat, tokoh masyarakat, kepolisian, keluarga dan warga masyarakat pada umumnya. Upaya pengendalian masalah ini tentunya tidak bisa hanya dalam satu waktu, dibutuhkan upaya keberlanjutan yang konsisten. Diharapkan semua pihak yang sudah disebutkan di atas menunjukkan perannya secara optimal dalam mempromosikan kesehatan dan keselamatan berkendara.

\section{REFERENSI}

Butcher, H. K., Bulechek, G. M., Dochterman, J. M. M., \& Wagner, C. M. (2018). Nursing Interventions classification (NIC)-E-Book. Amsterdam: Elsevier Health Sciences. 
Chrussiawanti, N. (2015). Hubungan tingkat pengetahuan dengan kepatuhan safety riding pada remaja di SMA Negeri 2 Sukoharjo. Skripsi. Surakarta: Sekolah Tinggi Ilmu Kesehatan Kusuma Husada.

Kominfo. (2017). Rata-rata tiga orang meninggal setiap jam akibat kecelakaan jalan. Retrieved May, 22, 2019, from https://kominfo.go.id/index.php/content/detail/10368/rata-ratatiga-orang-meninggal-setiap-jam-akibat-kecelakaan-jalan/0/artikel_gpr

Kusmagi, M. Ag. (2010). Selamat berkendara di jalan raya. Jakarta: Raih Asa Sukses.

Marsaid, M., Hidayat, M., \& Ahsan, A. (2013). Faktor yang berhubungan dengan kejadian kecelakaan lalu lintas pada pengendara sepeda motor di wilayah Polres Kabupaten Malang. Jurnal Ilmu Keperawatan, 1(2), 98-112.

Pemerintah Republik Indonesia. (2009). Undang-Undang No 22 tentang Lalu Lintas dan Angkutan Jalan. Jakarta: Kementerian Hukum dan HAM.

Sumiyanto, A., Mahawati, E., \& Hartini, E. (2014). Pengaruh sikap individu dan perilaku teman sebaya terhadap praktik safety riding pada remaja (Studi kasus siswa SMA Negeri 1 Semarang). VISIKES: Jurnal Kesehatan Masyarakat, 13(2), 2-13.

World Health Organization. (2009). Global status report on road safety time for action. Jenewa, Swiss: World health organization.

World Health Organization. (2013). Road traffic injuries. Jenewa, Swiss: World Health Organization. 